\title{
The impact of body mass index on morbidity and short- and long-term mortality in cardiac valvular surgery
}

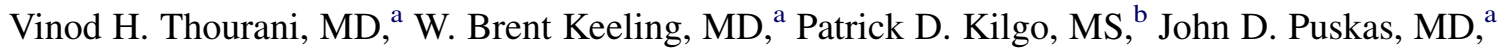 \\ Omar M. Lattouf, MD, PhD, ${ }^{\mathrm{a}}$ Edward P. Chen, MD, ${ }^{\mathrm{a}}$ and Robert A. Guyton, $\mathrm{MD}^{\mathrm{a}}$
}

Objective: Limited data exist on patients with cardiac cachexia or morbid obesity presenting for valvular heart surgery. The objective of this study was to investigate the relationship between body mass index and morbidity and mortality after valvular surgery.

\begin{abstract}
Methods: A retrospective review of 4247 patients undergoing valvular surgery from 1996 to 2008 at Emory University Healthcare Hospitals was performed. Patients were divided into 3 groups: body mass index 24 or less (group $1, \mathrm{n}=1527$ ), body mass index 25 to 35 (group $2, \mathrm{n}=2284$ ), and body mass index 36 or more (group $3, \mathrm{n}=436$ ). Data were analyzed using multivariable regression analysis, adjusted for 10 preoperative covariates. A smooth kernel regression curve was generated using body mass index and in-hospital mortality as variables. Long-term survival comparisons were made using adjusted Cox proportional hazards regression models and Kaplan-Meier product-limit estimates. Kaplan-Meier curves were generated that provide survival estimates for long-term mortality using the Social Security Death Index.
\end{abstract}

Results: Patients in group 3 were significantly younger (group 1, $61.7 \pm 16.1$ years; group 2, $61.9 \pm 13.6$; group $3,57.5 \pm 13.0 ; P<.001$ ) and more likely to be female (group 1, 778/1527 [51.0\%]; group 2, 912/2284 [39.9\%]; group 3, 240/436 [55.0\%]; $P<.001)$. Mean ejection fractions were similar among groups $(P=.51)$. Patients in group 2 had significantly shorter postoperative length of stay (group 1, $9.6 \pm 10.3$ days; group 2, $8.7 \pm 8.2$ days; group 3, $10.8 \pm 11.0$ days; $P<.001)$. In-hospital mortality for the entire cohort was $5.8 \%(245 / 4247)$, and by group was 111 of $1527(7.3 \%)$ in group 1, 110 of $2284(4.8 \%)$ in group 2, and 24 of $436(5.5 \%)$ in group $3(P=.006)$. Actual survival at $1,3,5$, and 10 years was significantly lower in group $1(P<.001)$. A lower body mass index was a significant independent predictor for both in-hospital and long-term mortality.

Conclusions: Patients with body mass index 24 or less are at significantly increased risk of in-hospital and longterm mortality after cardiac valvular surgery. This high-risk patient population warrants careful risk stratification and options for less-invasive valve therapies. (J Thorac Cardiovasc Surg 2011;142:1052-61)

It has been well defined that obesity has a major influence on the development of cardiovascular disease, leading to worsening physical function and quality of life. ${ }^{1,2}$ The alterations to the vascular endothelium as a consequence of obesity include promotion of atherosclerosis, alteration in cardiac ventricular load and efficiency, promotion of

From the Clinical Research Unit, ${ }^{a}$ Division of Cardiothoracic Surgery, Joseph B Whitehead Department of Surgery, Emory University School of Medicine, Atlanta, $\mathrm{Ga}$; and Department of Biostatistics, ${ }^{\mathrm{b}}$ Rollins School of Public Health, Emory University School of Medicine, Atlanta, Ga.

Funding by internal funds from the Division of Cardiothoracic Surgery Clinical Research Unit.

Disclosures: Vinod H. Thourani: Edwards LifeSciences: speaker, research; St Jude: Advisory Board; Sorin Medical: speaker; Medtronic: speaker. W. Brent Keeling: none. Patrick D. Kilgo: none. Edward Chen: none. Omar M. Lattouf: none. John D. Puskas, MD: Medtronic: speaker, Advisory Board. Robert A. Guyton, MD: none.

Received for publication Nov 8, 2010; revisions received Jan 13, 2011; accepted for publication Feb 9, 2011; available ahead of print March 30, 2011.

Address for reprints: Vinod H. Thourani, MD, Associate Professor of Surgery, 550 Peachtree Street, Crawford Long Hospital, 6th Floor, Medical Office Tower, Cardiothoracic Surgery, Atlanta, GA 30308 (E-mail: vthoura@emory.edu).

0022-5223/ $\$ 36.00$

Copyright $(2011$ by The American Association for Thoracic Surgery doi:10.1016/j.jtcvs.2011.02.009 adverse inflammatory milieu, and predisposition to proteinuria and renal dysfunction. ${ }^{3}$ In light of the changes to the vascular endothelium and the prevalence of obesityrelated coronary artery disease in the United States, the majority of the literature regarding outcomes of obese patients has concentrated on those undergoing coronary artery bypass grafting $(\mathrm{CABG})$ or mixed cardiac surgical populations. ${ }^{4-13}$

Correspondingly, patients presenting with malnutrition represent another high-risk group presenting with cardiovascular disease. In contrast with obesity, malnutrition is an often overlooked preoperative comorbid condition in patients undergoing cardiac surgery. ${ }^{14}$ Although some have noted that malnutrition increases short-term morbidity and mortality after cardiac operations, ${ }^{15-17}$ others have shown more favorable in-hospital outcomes. ${ }^{5}$ Studies evaluating malnutrition have concentrated on patients undergoing CABG.

The current study investigated the relationship between body mass index (BMI) and morbidity and mortality in 4247 patients undergoing cardiac valvular surgery. Specifically, we evaluated unadjusted in-hospital morbidity and 

Abbreviations and Acronyms
AVR = aortic valve replacement
BMI = body mass index
$\mathrm{CABG}=$ coronary artery bypass grafting
CI = confidence interval
NYHA $=$ New York Heart Association
STS = Society of Thoracic Surgeons

mortality and long-term all-cause survival within different quartiles of BMI values.

\section{MATERIALS AND METHODS}

This study sought to characterize the relationship between BMI and clinical outcomes after valve surgery. For descriptive purposes, patients were classified into 3 groups according to their BMI classification by O'Brien and colleagues: ${ }^{18}$ (1) 24 or less, (2) 25 to 35 , and (3) 36 or more. Patients were identified by querying the institutional Society of Thoracic Surgeons (STS) Adult Cardiac Database for consecutive patients who underwent valve surgery at Emory Healthcare Hospitals between January 1, 1996, and June 30, 2008. Patients with concomitant CABG were included, and patients undergoing emergency operation or operation under salvage conditions were excluded.

During this period, 4649 consecutive patients underwent valve surgery. Of these, 4247 patients $(91.4 \%)$ had the available data to calculate BMI. Thus, 402 patients were excluded because their BMI control was missing. Extracted records included demographic data, preexisting comorbidities, and clinical outcomes. The study was approved by the Emory University Institutional Review Board in compliance with Health Insurance Portability and Accountability Act regulations and the Declaration of Helsinki. The institutional review board waived individual patient consent secondary to the retrospective nature of the study.

\section{Interventions, Surgeons, and Surgical Technique}

Each patient underwent a single surgical session performed at the discretion of any of 19 faculty surgeons. Cardiac catheterization was performed in all patients aged more than 40 years or in younger patients with risk factors for coronary artery disease. Standard cardiopulmonary bypass techniques for valve operations were used in all patients. Surgical approach, valve prosthesis or repair techniques, and conduct of cardiopulmonary bypass and myocardial protection were left to the discretion of the attending cardiac surgeon. Typically, conventional cardiopulmonary bypass was performed using roller head pumps, membrane oxygenators, cardiotomy suction, arterial filters, cold antegrade and retrograde blood cardioplegia, and moderate systemic hypothermia $\left(32^{\circ} \mathrm{C}-34^{\circ} \mathrm{C}\right)$. The operative field was routinely flooded with carbon dioxide, and de-airing maneuvers were performed in all cases before releasing the crossclamp.

\section{Long-Term Follow-up}

The Social Security Death Index is a publicly available national database of death records extracted from the US Social Security Administration's Death Master File Extract. Patients with a Social Security Number who have died since 1963 and whose death has been reported to the Social Security Administration will be listed in the Social Security Death Index. For each patient who died before the cutoff date of June 30, 2008, a mortality date was provided, allowing Kaplan-Meier long-term survival curves. Cause of death is not available; thus, this study describes all-cause longterm mortality.

\section{Variables of Interest}

Before analysis, 22 preoperative risk factors for the outcomes of interest were identified and harvested from the STS database (Table 1). Standard STS definitions for each risk factor and outcome were used. Race was dichotomized as Caucasian or non-Caucasian. Chronic lung disease was ordinally measured in some later years and dichotomously measured in earlier years; in this study it was dichotomized. New York Heart Association (NYHA) heart failure classification was dichotomized as class III/IV or I/II. The primary outcomes examined in this study were in-hospital mortality and long-term survival; secondary end points included permanent stroke (cerebrovascular accident), myocardial infarction, the composite end point for any of these major adverse cardiac, and cerebrovascular events and operative reintervention.

The institutional medical records STS database was populated by trained personnel devoted exclusively to data management; thus, missing data were scarce. Data were $100 \%$ complete for each major postoperative hospital outcome. Data were missing for the following preoperative characteristics: NYHA classification III/IV $(\mathrm{n}=1376,32.4 \%)$, ejection fraction $(\mathrm{n}=771,18.2 \%)$, last creatinine level $(\mathrm{n}=735,17.3 \%)$, and Caucasian race $(\mathrm{n}=336,7.9 \%)$.

\section{Data Management and Statistical Analysis}

All data for consecutive patients were entered into a computerized surgical database, using the fields and definitions of the STS National Adult Cardiac Database. Checks for data quality were used at the institutional level and before final entry into the STS national adult cardiac database.

A multiple imputation algorithm was used to impute missing values so that the whole sample could be analyzed. This was not done in an effort to re-create the truth; rather, the goal of the imputation was to avoid selection bias that can occur by deleting cases with missing variables of interest.

To initially evaluate the relationship between BMI and in-hospital mortality, kernel estimation smoothing was used. To this end, a plot was created where the $\mathrm{x}$-axis was BMI and the $\mathrm{y}$-axis was observed in-hospital mortality. Because observed mortality is dichotomous, the points on the plot at each BMI value are calculated by taking an average of the observed mortality (so-called uniform kernel smoothing) for a "neighborhood" around the BMI value. The neighborhood is the collection of points within a small range around the BMI value; thus, the point on the plot is the average mortality rate for that small region of BMI values. The width of the neighborhood was set at $15 \%$, meaning that each point plotted represents a moving average of $30 \%$ of the data.

To statistically evaluate the effects of BMI on in-hospital mortality, a multivariable logistic regression model was constructed. The model contains 10 additional preoperative covariates to adjust for potential selection bias: age, sex, dialysis, renal failure, heart failure, ejection fraction, presence of concomitant CABG, infectious endocarditis, previous stroke, and chronic lung disease. According to the smoothed curve, it was determined that BMI has a parabolic relationship with mortality; thus, BMI and $\mathrm{BMI}^{2}$ were entered as a quadratic chunk into the regression model and evaluated as a chunk. Adjusted odds ratios associated with BMI and other covariates, along with $95 \%$ confidence intervals (CIs), were computed.

Long-term survival comparisons were made using adjusted Cox proportional hazards regression models and Kaplan-Meier product-limit estimates (unadjusted). Kaplan-Meier curves were generated that provide survival estimates at postoperative points in time. Differences between BMI classifications were determined by log-rank tests. These estimates include operative deaths.

Adjusted long-term survival comparisons were made by using proportional hazards regression to model the instantaneous hazard of death as a function of BMI and $\mathrm{BMI}^{2}$, adjusted for age, sex, dialysis, renal failure, heart failure, ejection fraction, presence of concomitant coronary artery bypass, infectious endocarditis, previous stroke, and chronic lung disease. 
TABLE 1. Preoperative characteristics

\begin{tabular}{|c|c|c|c|c|}
\hline Characteristic & $\begin{array}{l}\text { BMI } \leq 24 \\
(n=1527)\end{array}$ & $\begin{array}{l}\text { BMI 25-35 } \\
(n=2284)\end{array}$ & $\begin{array}{c}\text { BMI } \geq 36 \\
(n=436)\end{array}$ & $P$ value \\
\hline Age (mean $\pm \mathrm{SD})$ & $61.7 \pm 16.1$ & $61.9 \pm 13.6$ & $57.5 \pm 13.0$ & $<.001$ \\
\hline Female gender & $778(50.9 \%)$ & $912(39.9 \%)$ & $240(55.0 \%)$ & $<.001$ \\
\hline Caucasian* & $1111(78.3 \%)$ & $1661(79.2 \%)$ & $281(71.3 \%)$ & .003 \\
\hline Status & & & & .046 \\
\hline Elective & $1293(84.7 \%)$ & $1966(86.1 \%)$ & $356(81.7 \%)$ & \\
\hline Urgent & $234(15.3 \%)$ & $317(13.9 \%)$ & $80(18.3 \%)$ & \\
\hline Ejection fraction $($ mean $\% \pm \mathrm{SD}$ ) $*$ & $53.0 \pm 13.5$ & $52.6 \pm 13.4$ & $53.3 \pm 12.8$ & .51 \\
\hline Hypertension & $855(56.0 \%)$ & $1540(67.0 \%)$ & $349(80.1 \%)$ & $<.001$ \\
\hline NYHA class 3 and $4 *$ & $475(46.5 \%)$ & $715(46.9 \%)$ & $169(52.3 \%)$ & .16 \\
\hline Diabetes & $186(12.2 \%)$ & $501(21.9 \%)$ & $164(37.6 \%)$ & $<.001$ \\
\hline COPD* & $273(17.9 \%)$ & $335(14.7 \%)$ & $101(23.2 \%)$ & $<.001$ \\
\hline Previous myocardial infarction & $236(15.5 \%)$ & $372(16.3 \%)$ & $78(17.9 \%)$ & .46 \\
\hline Previous CVA & $152(10.0 \%)$ & $183(8.0 \%)$ & $34(7.8 \%)$ & .09 \\
\hline Previous valve surgery & $108(33.6 \%)$ & $108(26.5 \%)$ & $10(13.2 \%)$ & $<.001$ \\
\hline Cerebrovascular disease & $229(15.0 \%)$ & $322(14.1 \%)$ & $63(14.5 \%)$ & .74 \\
\hline Peripheral vascular disease & $100(6.6 \%)$ & $147(6.4 \%)$ & $22(5.1 \%)$ & .50 \\
\hline Mean preoperative serum creatinine* & $1.46 \pm 1.68$ & $1.38 \pm 1.50$ & $1.38 \pm 1.45$ & .30 \\
\hline Chronic renal insufficiency & $178(11.7 \%)$ & $204(8.9 \%)$ & $48(11.0 \%)$ & .019 \\
\hline Preoperative dialysis & $82(5.4 \%)$ & $80(3.5 \%)$ & $20(4.6 \%)$ & .019 \\
\hline Infectious endocarditis & $167(10.9 \%)$ & $168(7.4 \%)$ & $31(7.1 \%)$ & $<.001$ \\
\hline Dyslipidemia & $298(19.5 \%)$ & $619(27.1 \%)$ & $159(36.5 \%)$ & $<.001$ \\
\hline Current smoker & $424(27.8 \%)$ & $664(29.1 \%)$ & $145(33.3 \%)$ & .08 \\
\hline Preoperative IABP & $8(0.5 \%)$ & $10(0.4 \%)$ & $2(0.5 \%)$ & .93 \\
\hline Immunosuppressive therapy & $85(5.6 \%)$ & $107(4.7 \%)$ & $29(6.7 \%)$ & .17 \\
\hline STS Predicted risk of mortality* & $4.9 \pm 5.2$ & $3.8 \pm 4.0$ & $3.5 \pm 3.7$ & $<.001$ \\
\hline
\end{tabular}

$B M I$, Body mass index; $S D$, standard deviation; NYHA, New York Heart Association; COPD, chronic obstructive pulmonary disease; CVA, cerebral vascular accident; IABP, intraaortic balloon pump. *Contains some missing data.

The proportional hazards assumption was verified via a correlation analysis of the Schoenfeld residuals and ranked follow-up time. Hazard ratios were generated for each model term, along with $95 \%$ CI.

Data were managed and analyzed using SAS Version 9.1 (SAS Institute Inc, Cary, NC). Unadjusted comparisons were performed with chi-square tests and 2-sample $t$ tests for categoric and continuous predictors, respectively. All statistical tests were 2-sided using an $\alpha=0.05$ level of significance. No adjustments for multiple tests were made.

\section{RESULTS}

\section{Preoperative and Operative Characteristics}

A total of 4247 patients underwent valve surgery at a single academic institution and comprise the study group. The patients were divided into 3 groups: group 1 (BMI $\leq 24$, $\mathrm{n}=1527$ ), group 2 (BMI, 25-35; $\mathrm{n}=2284$ ), and group 3 $(\mathrm{BMI} \geq 36, \mathrm{n}=436)$. Preoperative characteristics are shown in Table 1. Notably, patients in group 3 were younger, more likely to be female, and more likely to have hypertension, diabetes mellitus, chronic obstructive pulmonary disease, and dyslipidemia. Patients in group 1 were more likely to have had previous valve surgery, preoperative dialysis, and infectious endocarditis. In all groups, approximately one half of patients were in NYHA class III or IV, and the ejection fraction was $53 \%$. The STS predicted risk of mortality was significantly higher in those patients with BMI 24 or less.
Table 2 describes operative procedures according to BMI group. Both aortic crossclamp and cardiopulmonary bypass times were significantly longer in group 3 . The most common valve surgery was aortic valve replacement (AVR) in all groups. Bioprosthetic valve implantation was similar among groups at approximately $50 \%$. CABG and placement of an intraoperative intraaortic balloon pump were more common in group 3 .

\section{In-Hospital Morbidity and Mortality}

Unadjusted in-hospital outcomes are described in Table 3. Overall, in-hospital mortality occurred in 245 patients $(5.8 \%)$. Mediastinitis, new renal failure, prolonged ventilation, and total initial intensive care unit length of stay were more common in group 3. However, in-hospital mortality was significantly greater in group 1 . The observed to STS predicted risk of mortality expected ratio was 1.48 in group $1,1.17$ in group 2, and 1.25 in group 3. After adjusting for 10 covariates using a multivariable logistic regression analysis (Table 4), BMI trended as an independent predictor for in-hospital mortality (odds ratio, $0.89 ; 95 \%$ CI, $0.78-1.01$; $P=.07)$. However, the following variables emerged as statistically significant predictors of in-hospital mortality: renal insufficiency, advanced age, female gender, endocarditis, and previous stroke. 
TABLE 2. Operative characteristics for each body mass index group

\begin{tabular}{|c|c|c|c|c|}
\hline Operative data & $\begin{array}{l}\mathrm{BMI} \leq \mathbf{2 4} \\
(\mathrm{n}=\mathbf{1 5 2 7})\end{array}$ & $\begin{array}{c}\text { BMI 25-35 } \\
(n=2284)\end{array}$ & $\begin{array}{c}\text { BMI } \geq 36 \\
(n=436)\end{array}$ & $P$ value \\
\hline \multirow[t]{2}{*}{ BMI } & $22.1 \pm 2.14$ & $28.9 \pm 2.7$ & $39.6 \pm 4.4$ & \multirow[t]{2}{*}{$<.001$} \\
\hline & Median: 22.5 & Median: 28.4 & Median: 38.3 & \\
\hline \multirow[t]{2}{*}{ Aortic crossclamp time (min) (mean $\pm \mathrm{SD})$} & $85.0 \pm 32.7$ & $90.4 \pm 32.5$ & $96.8 \pm 37.7$ & \multirow[t]{2}{*}{$<.001$} \\
\hline & Median: 80.0 & Median: 85 & Median: 89 & \\
\hline \multirow[t]{2}{*}{$\mathrm{CPB}$ time $(\min )($ mean $\pm \mathrm{SD})$} & $123.3 \pm 46.5$ & $127.5 \pm 42.6$ & $135.0 \pm 51.0$ & \multirow[t]{2}{*}{$<.001$} \\
\hline & Median: 114 & Median: 120 & Median: 123 & \\
\hline Isolated primary AVR & $614(40.2 \%)$ & $1144(50.1 \%)$ & $246(56.4 \%)$ & $<.001$ \\
\hline \multirow[t]{2}{*}{ AVR valve size implanted } & $22.7 \pm 2.4$ & Mean: $23.3 \pm 2.5$ & Mean: $23.4 \pm 2.4$ & \multirow[t]{2}{*}{$<.001$} \\
\hline & Median: 23 & Median: 23 & Median: 23 & \\
\hline Isolated primary MV procedure & $449(29.4 \%)$ & $573(25.1 \%)$ & $82(18.8 \%)$ & $<.001$ \\
\hline Double valve procedure & $205(13.4 \%)$ & $205(9.0 \%)$ & $41(9.4 \%)$ & $<.001$ \\
\hline Other valve procedures & $242(15.9 \%)$ & $212(9.3 \%)$ & $46(10.6 \%)$ & $<.001$ \\
\hline Concomitant CABG & $443(29.0 \%)$ & $818(35.8 \%)$ & $142(32.6 \%)$ & $<.001$ \\
\hline Bioprosthetic valve & $791(51.8 \%)$ & $1131(49.5 \%)$ & $216(49.5 \%)$ & .36 \\
\hline Intraoperative IABP insertion & $60(3.9 \%)$ & $126(5.5 \%)$ & $33(7.6 \%)$ & .005 \\
\hline
\end{tabular}

$B M I$, Body mass index; $S D$, standard deviation; $C P B$, cardiopulmonary bypass; $A V R$, aortic valve replacement; $M V$, mitral valve; $C A B G$, coronary artery bypass grafting; $I A B P$, intra-aortic balloon pump.

To evaluate the relationship between BMI and in-hospital mortality, kernel estimation smoothing was used and is represented in Figures 1 to 5. An initial analysis of all patients (Figure 1) reveals the lowest in-hospital mortality in those patients with a normal BMI. Furthermore, this bimodal curve reveals the highest mortality in those with the lowest BMI and increasing mortality in those with a BMI greater than 32. Further analysis revealed a similar curve for those

TABLE 3. Unadjusted short-term postoperative outcomes for each age group

\begin{tabular}{|c|c|c|c|c|}
\hline Outcomes & $\begin{array}{l}\mathrm{BMI} \leq \mathbf{2 4} \\
(\mathrm{n}=\mathbf{1 5 2 7})\end{array}$ & $\begin{array}{c}\text { BMI 25-35 } \\
(n=2284) \\
\end{array}$ & $\begin{array}{c}\text { BMI } \geq 36 \\
(n=436)\end{array}$ & $P$ value \\
\hline Myocardial infarction & $7(0.5 \%)$ & $15(0.7 \%)$ & $2(0.5 \%)$ & .69 \\
\hline Cerebral vascular accident & $48(3.1 \%)$ & $50(2.2 \%)$ & $14(3.2 \%)$ & .14 \\
\hline Mediastinitis & $7(0.5 \%)$ & $18(0.8 \%)$ & $13(3.0 \%)$ & $<.001$ \\
\hline Septicemia & $59(3.9 \%)$ & $60(2.6 \%)$ & $19(4.4 \%)$ & .042 \\
\hline Heart block requiring pacemaker & $51(3.3 \%)$ & $80(3.5 \%)$ & $14(3.2 \%)$ & .94 \\
\hline Multisystem failure & $35(2.3 \%)$ & $34(1.5 \%)$ & $12(2.8 \%)$ & .08 \\
\hline New renal failure & $105(6.9 \%)$ & $129(5.7 \%)$ & $41(9.4 \%)$ & .01 \\
\hline New dialysis & $34(2.2 \%)$ & $53(2.3 \%)$ & $12(2.8 \%)$ & .81 \\
\hline Reexploration bleeding & $113(7.4 \%)$ & $117(5.1 \%)$ & $17(3.9 \%)$ & .003 \\
\hline $\begin{array}{l}\text { Need for intraoperative } \\
\text { PRBC transfusion }\end{array}$ & $398(26.1 \%)$ & $542(23.7 \%)$ & $95(21.8 \%)$ & .11 \\
\hline Mean PRBC unit transfused & $0.83 \pm 1.75$ & $0.74 \pm 1.67$ & $0.75 \pm 1.82$ & .26 \\
\hline Postoperative pneumonia & $105(6.9 \%)$ & $131(5.7 \%)$ & $31(7.1 \%)$ & .28 \\
\hline $\begin{array}{l}\text { Postoperative ventilator (h) } \\
\quad(\text { mean } \pm \mathrm{SD})\end{array}$ & $\begin{array}{c}41 \pm 118 \\
\text { Median: } 11\end{array}$ & $\begin{array}{r}37 \pm 110 \\
\text { Median: } 8\end{array}$ & $\begin{array}{c}58 \pm 152 \\
\text { Median: } 12.9\end{array}$ & .004 \\
\hline Prolonged ventilation & $190(12.4 \%)$ & $289(12.7 \%)$ & $93(21.3 \%)$ & $<.001$ \\
\hline Postoperative IABP insertion & $14(0.9 \%)$ & $16(0.7 \%)$ & $3(0.7)$ & .74 \\
\hline New-onset atrial fibrillation & $359(23.5 \%)$ & $568(24.9 \%)$ & $103(23.6 \%)$ & .60 \\
\hline Gastrointestinal complication & $78(5.2 \%)$ & $92(4.0 \%)$ & $20(4.6 \%)$ & .25 \\
\hline $\begin{array}{l}\text { Total initial ICU LOS }(\mathrm{h}) \\
\quad(\text { mean } \pm \mathrm{SD})\end{array}$ & $\begin{array}{c}107 \pm 177 \\
\text { Median: } 47.0\end{array}$ & $\begin{array}{c}99 \pm 174 \\
\text { Median: } 45.2\end{array}$ & $\begin{array}{l}129 \pm 206 \\
\text { Median: } 51\end{array}$ & .035 \\
\hline $\begin{array}{l}\text { Postoperative LOS }(\mathrm{d}) \\
\quad(\text { mean } \pm \mathrm{SD})\end{array}$ & $\begin{array}{l}9.6 \pm 10.3 \\
\text { Median: } 6\end{array}$ & $\begin{array}{l}8.7 \pm 8.2 \\
\text { Median: } 6\end{array}$ & $\begin{array}{l}10.8 \pm 11.0 \\
\text { Median: } 7\end{array}$ & $<.001$ \\
\hline In-hospital mortality & $111(7.3 \%)$ & $110(4.8 \%)$ & $24(5.5 \%)$ & .006 \\
\hline STS PROM* $*$ & $4.9 \pm 5.2$ & $3.8 \pm 4.0$ & $3.5 \pm 3.7$ & $<.001$ \\
\hline $\mathrm{O} / \mathrm{E}$ mortality & $7.3 / 4.9=1.5(\mathrm{n}=907)$ & $4.5 / 3.8=1.17(\mathrm{n}=1467)$ & $4.4 / 3.5=1.25(\mathrm{n}=295)$ & \\
\hline
\end{tabular}

$B M I$, Body mass index; $S D$, standard deviation; $P R B C$, packed red blood cell; IABP, intra-aortic balloon pump; ICU, intensive care unit; $L O S$, length of stay; STS, Society of Thoracic Surgeons; PROM, predicted risk of mortality; $O / E$, observed to expected. *Data missing. 
TABLE 4. Estimates of preoperative predictors of in-hospital survival from multivariable logistic regression analysis

\begin{tabular}{lcc}
\hline \multicolumn{1}{c}{ Preoperative variables } & $\begin{array}{c}\text { Odds ratio } \\
(\mathbf{9 5} \% \mathbf{C I})\end{array}$ & $\boldsymbol{P}$ value \\
\hline Age & $1.04(1.03-1.06)$ & $<.00001$ \\
Chronic lung disease & $1.13(0.81-1.58)$ & .48 \\
CVA & $1.45(0.98-2.13)$ & .06 \\
EF & $0.99(0.98-1.00)$ & .19 \\
Infectious endocarditis & $1.78(1.11-2.85)$ & .02 \\
Female gender & $1.79(1.35-2.36)$ & .00004 \\
Heart failure & $1.23(0.92-1.65)$ & .16 \\
Renal failure & $2.44(1.61-3.70)$ & .00002 \\
Renal failure requiring dialysis & $2.36(1.35-4.10)$ & .002 \\
CAD requiring CABG & $1.32(0.99-1.76)$ & .06 \\
BMI & $0.89(0.78-1.01)$ & .07 \\
\hline
\end{tabular}

$C V A$, Cerebrovascular accident; $E F$, ejection fraction; $C A D$, coronary artery disease; $C A B G$, coronary artery bypass grafting; $B M I$, body mass index.

undergoing isolated AVR (Figure 2). In those undergoing isolated mitral valve procedures (Figure 3), multiple valve procedures (Figure 4), or concomitant CABG (Figure 5), there was a significant increased mortality in those with a lower BMI.

\section{Long-term Mortality}

The median follow-up for all patients was 4.4 years. Survival estimates for each group are shown in Table 5 and in the Kaplan-Meier curve in Figure 6. When all patients were grouped according to BMI status, 10-year survival was significantly reduced among patients with a BMI of 24 or less compared with those with higher BMI status (group 1: $53.5 \%$ vs group $2: 63.4 \%$ vs group $3: 62.2 \% ; P<.001$ ).
After multivariable adjustment, BMI was associated with reduced long-term survival (hazard ratio, $0.91 ; 95 \% \mathrm{CI}$, $0.86-0.97 ; P=.002$ ). Other significant independent predictors of long-term mortality are listed in Table 6 and include renal failure, older age, female sex, heart failure, endocarditis, stroke, and chronic lung disease.

\section{DISCUSSION}

Although data on malnourished surgical patients have existed for some time, the role of low BMI as a risk factor for morbidity and mortality has been largely ignored, likely because of the burgeoning epidemic of obesity in the United States. This study serves to add to the growing body of literature detailing increased morbidity and mortality in patients with low BMI after cardiac surgery. No study to date has examined the relationship between BMI and outcomes in patients undergoing strictly cardiac valvular procedures.

Similar to prior studies on this topic, the current study showed that obese patients (BMI $>35$ ) had a higher incidence of certain morbidities and resource use after valvular surgery. ${ }^{19,20}$ They experienced longer cardiopulmonary bypass times, longer aortic crossclamp times, and a higher rate of intraoperative balloon counterpulsation. Accordingly, they also experienced a greater degree of postoperative renal failure, mediastinitis, and prolonged ventilation. Although these patients had prolonged intensive care unit and hospital stay leading to increased resource use, they did not have greater in-hospital mortality $(5.5 \%)$ when compared with patients with normal BMI $(4.8 \%)$ and patients with

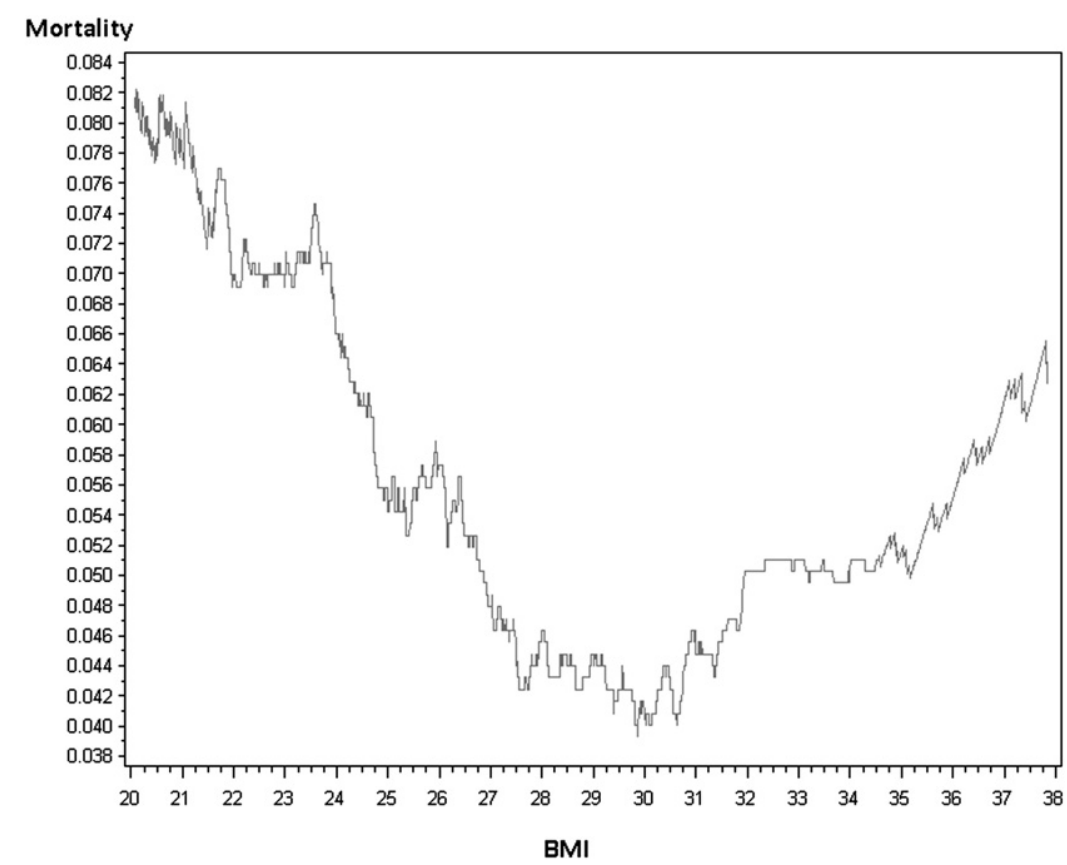

FIGURE 1. Smooth kernel estimation of in-hospital mortality for the BMI range of all patients. BMI, Body mass index. 


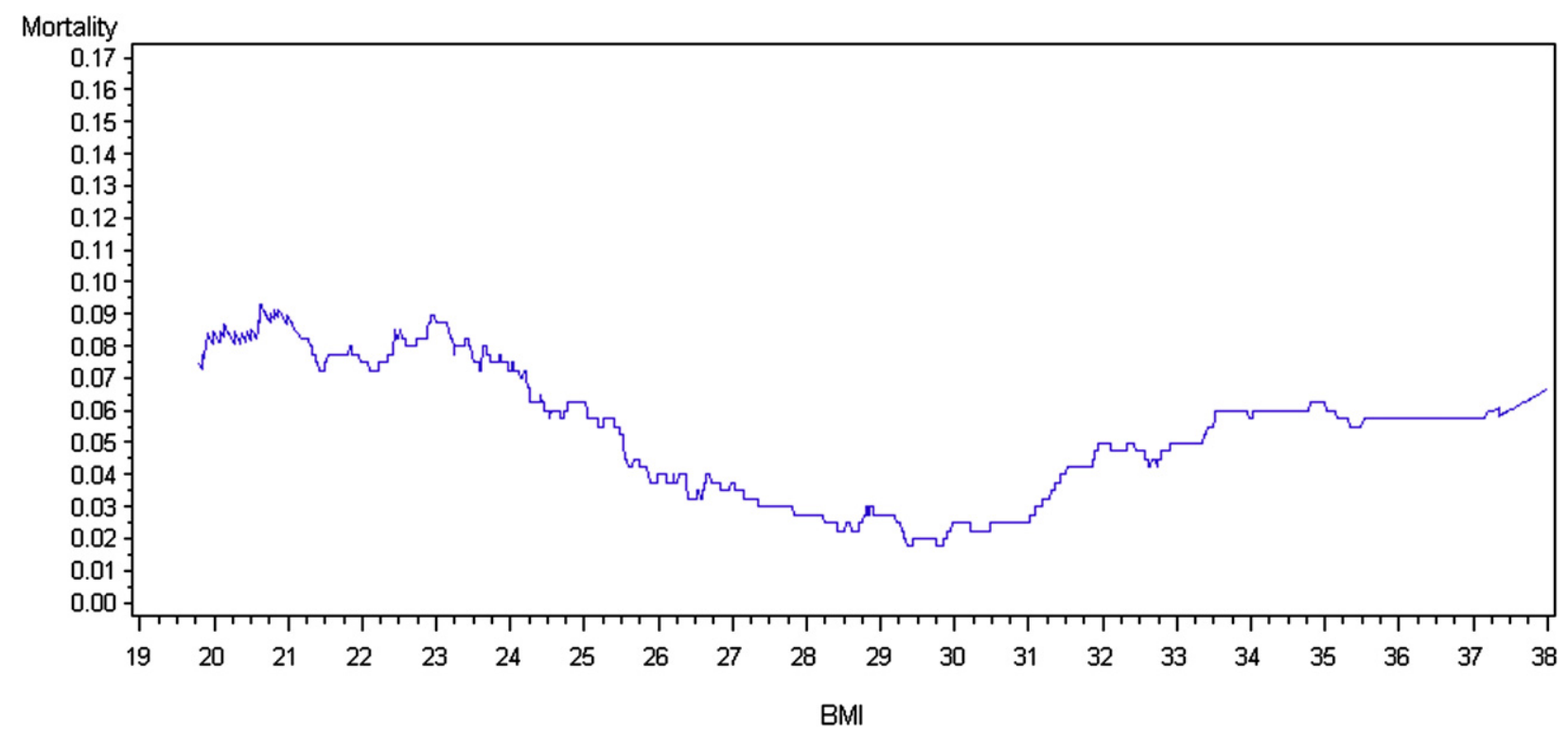

FIGURE 2. Smooth kernel estimation of in-hospital mortality for the BMI range of patients undergoing isolated AVR. BMI, Body mass index.

the lowest BMI $(7.3 \%)$. These data are consistent with other researchers who have noted an "obesity paradox" in a mixed cardiac surgical population showing decreased in-hospital and long-term mortality when compared with normalweight patients. ${ }^{12}$ It is plausible that obese patients likely self-select, and those who undergo surgery have greater functional reserve than patients with low BMI. These similar trends for the obese patients reveal a 10-year survival similar to that of patients with normal BMI and significantly higher survival than that of patients with the lowest BMI. Data exist supporting the fact that overweight patients have lower mortality after cardiovascular events associated with coronary artery disease and lower mortality from heart failure. ${ }^{3,21}$

Outcomes delineating the effects of malnutrition for patients undergoing cardiac surgery have been sparingly evaluated. Engelman and colleagues ${ }^{15}$ evaluated a mixed

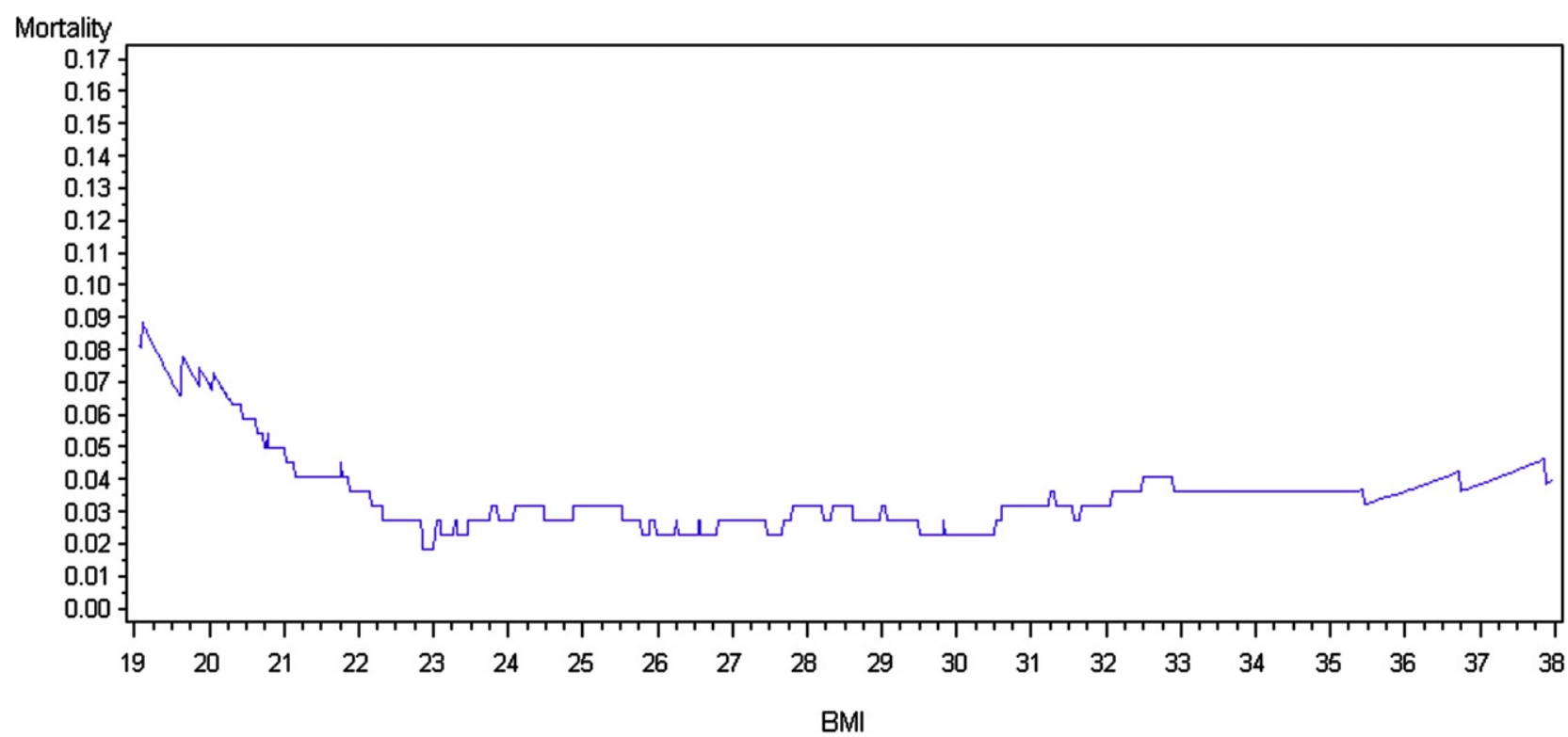

FIGURE 3. Smooth kernel estimation of in-hospital mortality for the BMI range of patients undergoing isolated mitral valve procedures. BMI, Body mass index. 


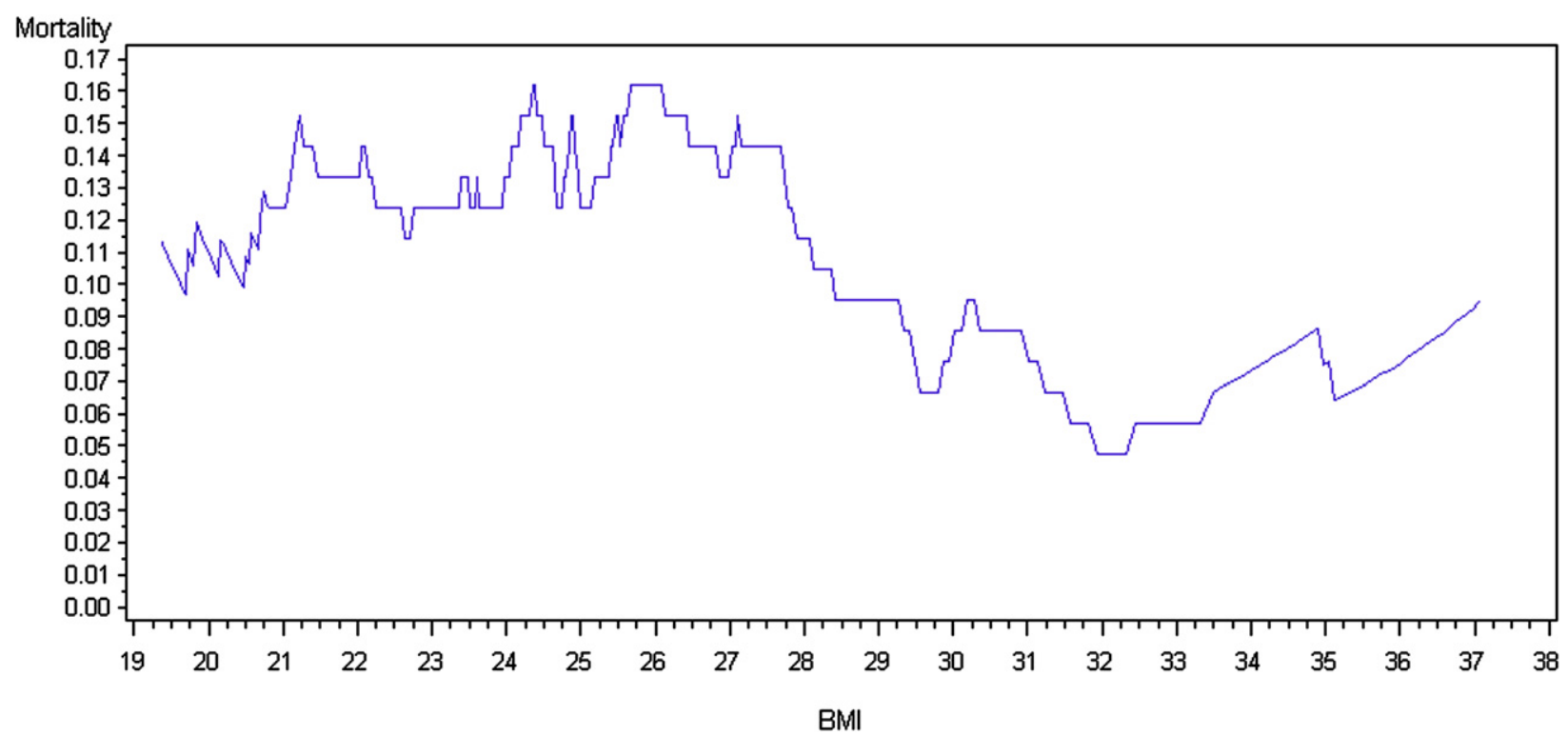

FIGURE 4. Smooth kernel estimation of in-hospital mortality for the BMI range of patients undergoing multiple valve procedures. BMI, Body mass index.

cardiac surgical population of patients undergoing both $\mathrm{CABG}$ and valvular surgery. In a study that included more than 5000 patients (68\% undergoing CABG), these researchers found that BMI less than 20 was independently associated with increased mortality, incidence of stroke, renal failure, and reexploration for hemorrhage after cardiopulmonary bypass. Although no plausible explanations were offered for the observed results in this study, the authors concluded that low BMI should be included in risk stratification models for cardiac surgery. In a population of more than 4000 patients undergoing isolated CABG in the United Kingdom, Reeves and colleagues ${ }^{9}$ found an increased incidence of in-hospital mortality, renal failure, and prolonged ventilation in patients with BMI less than 20. Potapov and colleagues ${ }^{17}$ published results of approximately 23,000 patients who underwent isolated CABG or CABG with valve surgery. The large number of patients in this study allowed researchers to separate patients into 20 separate BMI groups. The results from this study confirmed prior data in that patients with low BMI were at

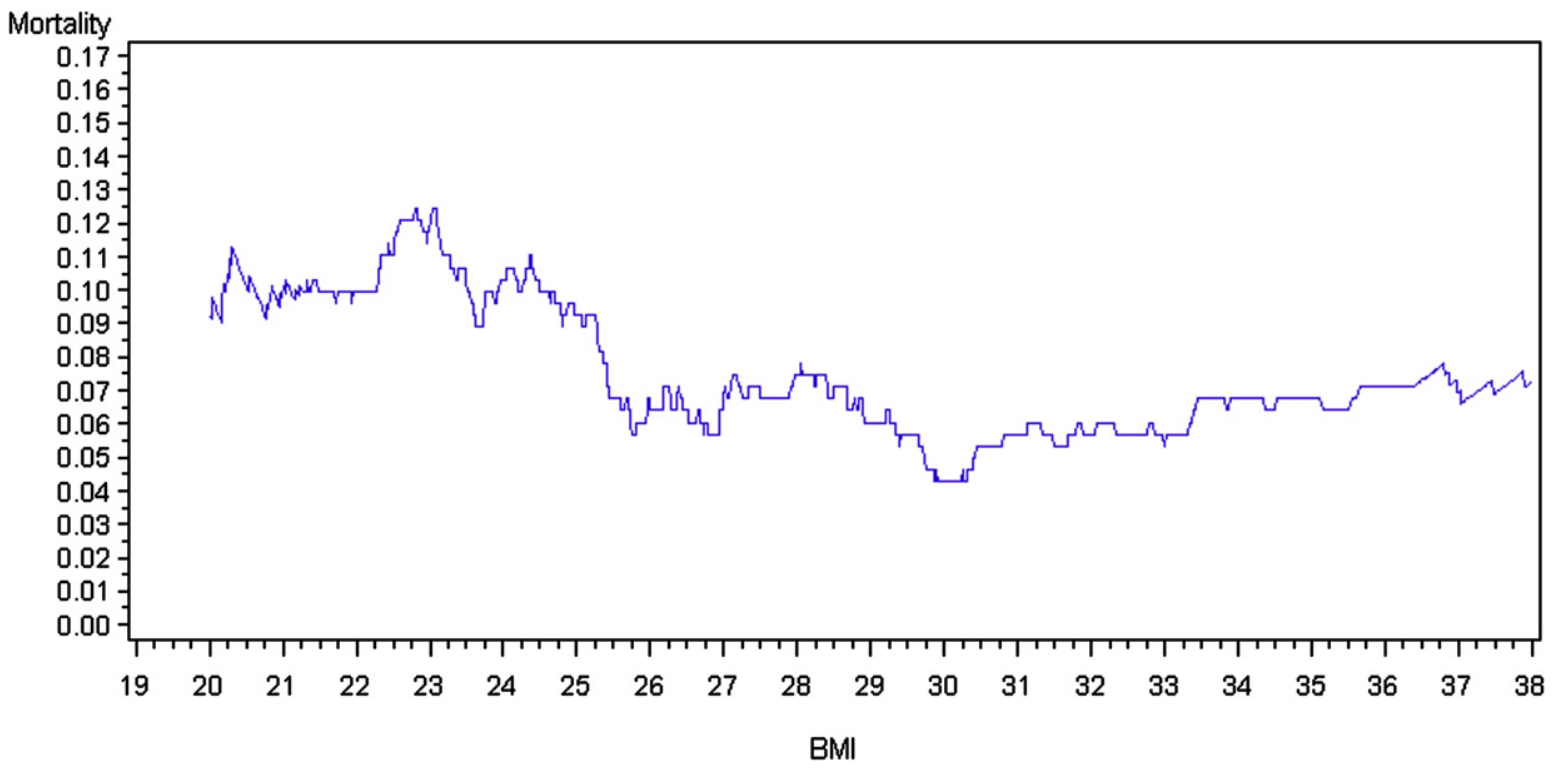

FIGURE 5. Smooth kernel estimation of in-hospital mortality for the BMI range of patients undergoing valve procedures with concomitant CABG. BMI, Body mass index. 
TABLE 5. Survival estimates for each age group

\begin{tabular}{lcccc}
\hline \multicolumn{1}{c}{ Age group } & 1-y survival & 3-y survival & 5-y survival & 10-y survival \\
\hline BMI $\leq 24(\mathrm{n}=1527)$ & $84.9 \%$ & $77.7 \%$ & $70.9 \%$ & $53.5 \%$ \\
BMI 25-35 $(\mathrm{n}=2284)$ & $89.2 \%$ & $84.5 \%$ & $78.3 \%$ & $63.4 \%$ \\
BMI $\geq 36(\mathrm{n}=436)$ & $88.1 \%$ & $80.2 \%$ & $73.3 \%$ & $62.2 \%$ \\
\hline
\end{tabular}

BMI, Body mass index.

increased risk for 30-day mortality, renal failure, reintubation, and reexploration for hemorrhage.

In the current series, patients with low BMI had the highest in-hospital mortality when compared with patients with normal and high BMI as indicated by the observed to expected ratios and smooth kernel curves (Figure 1). The bimodal curves associated with in-hospital mortality were similar for those undergoing isolated AVR (Figure 2) and all patients undergoing valve surgery (Figure 1). However, the bimodal nature of the curves was not apparent in those undergoing mitral valve procedures, multiple valve surgeries, or concomitant CABG (Figures 3-5), with an increased in-hospital mortality highest among patients with a low BMI and morbidly obese patients. Although epidemiologic data suggest U- or J-shaped curves in relation to BMI and mortality, ${ }^{2,22}$ the pathophysiologic perturbations of these curves in patients undergoing valvular surgery deserve further investigation.

It is plausible that patients who are underweight, when compared with patients with higher BMI, may not have the necessary metabolic reserve to overcome the further increased catabolic stress resulting from a stressful operation. ${ }^{3}$ In addition, a low BMI has been associated with increased hemodilution during cardiopulmonary bypass and a greater postoperative coagulopathy, whereas obesity has been associated with a protective effect on postoperative hemorrhage. ${ }^{4}$ Ranucci and colleagues ${ }^{23}$ have detailed an increased risk of postoperative hemorrhage requiring reexploration in patients with a low BMI. Although we did note an increased reexploration rate in group 1 in the current study, there was no difference in red cell transfusion among groups. The correlation of hypoalbuminemia as a surrogate for overall nutrition and poor outcomes after cardiac surgery remains divided. ${ }^{15,24,25}$

In addition to in-hospital morbidity and mortality, the current study evaluated all-cause long-term mortality in the low, normal, and high BMI groups. We have demonstrated a significant decrease in long-term survival associated with low BMI compared with the other BMI groups. Although patients in the low BMI group had more comorbidities and a greater preoperative predicted risk of mortality, they had greater long-term mortality that was unpredicted by a standard preoperative risk assessment tool. Prior studies have shown BMI and outcomes to be independent of nutritional status, ${ }^{15}$ and malnutrition alone does not seem to explain the results observed in this study. One explanation that relates to BMI is that of frailty and functional status. Frailty, as proposed by Fried and associates, ${ }^{26}$ includes such functional measures as unintentional weight loss of more than 10 pounds, low physical activity, and grip strength.

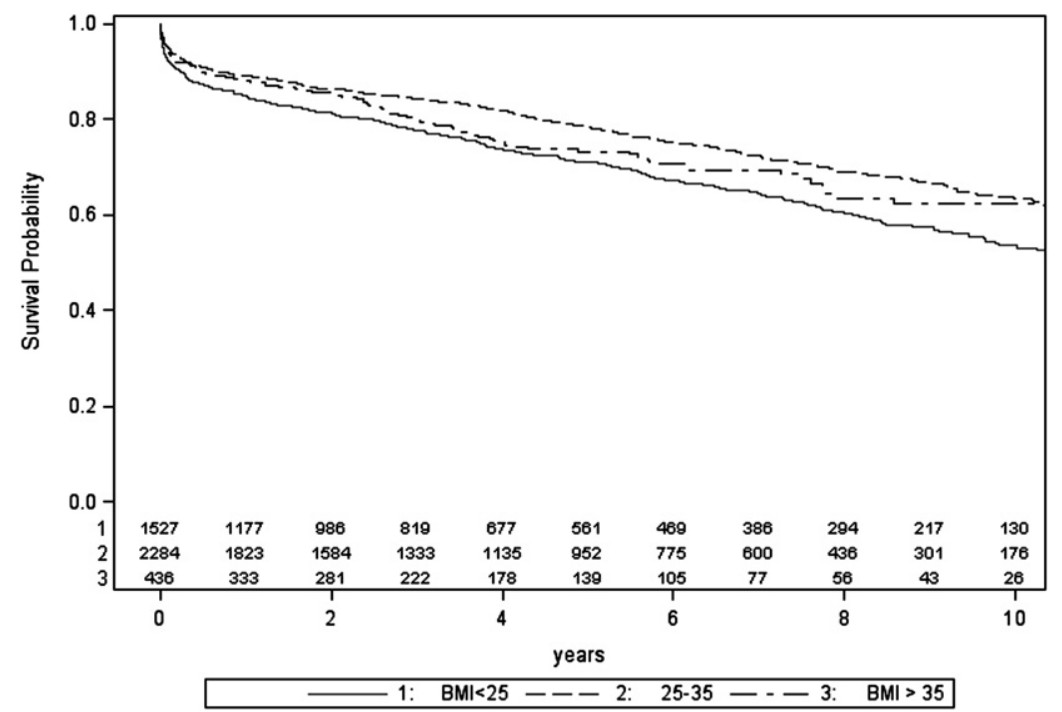

FIGURE 6. Kaplan-Meier survival estimates for patients with BMI 24 or less, 25 to 35 , and 36 or more. $P<.001$. BMI, Body mass index. 
TABLE 6. Significant preoperative predictors of long-term survival from multivariable survival analysis

\begin{tabular}{lcc}
\hline \multicolumn{1}{c}{ Preoperative variables } & $\begin{array}{c}\text { Hazard ratio } \\
(\mathbf{9 5} \% \mathbf{C I})\end{array}$ & $\boldsymbol{P}$ value \\
\hline Age & $1.04(1.03-1.04)$ & $<.00001$ \\
Chronic lung disease & $1.50(1.30-1.72)$ & $<.00001$ \\
CVA & $1.56(1.32-1.85)$ & $<.00001$ \\
EF & $0.99(0.99-1.00)$ & .04 \\
Infectious endocarditis & $1.58(1.28-1.95)$ & .00002 \\
Female gender & $1.27(1.12-1.43)$ & .0002 \\
Heart failure & $1.393(1.22-1.58)$ & $<.00001$ \\
Renal failure & $2.17(1.80-2.61)$ & $<.00001$ \\
Renal failure requiring dialysis & $2.69(2.07-3.50)$ & $<.00001$ \\
CAD requiring CABG & $1.29(1.13-1.47)$ & .0001 \\
BMI & $0.91(0.86-0.97)$ & .002 \\
\hline CVA, Cer
\end{tabular}

$C V A$, Cerebrovascular accident; $E F$, ejection fraction; $C A D$, coronary artery disease $C A B G$, coronary artery bypass grafting; $B M I$, body mass index.

Performance status is currently unaccounted for by the 3 major metrics used to predict mortality from cardiac surgery (STS, Parsonnet, euroSCORE). The inclusion of performance status or frailty scores in addition to BMI may improve the accuracy of these mortality predictions. Also, as newer technologies become available that obviate the need for cardiopulmonary bypass (eg, percutaneous and transapical valve technologies), patients with low BMI may benefit from avoidance of bypass and the attendant inflammatory response. Finally, in those patients for whom valve surgery is elective, a nutritional and physical enhancement program under the direction of trained professionals may serve to reduce morbidity and mortality.

\section{Limitations}

This study is limited by its observational nature and the inherent limitations of a retrospective database study. Although we controlled for confounding variables using logistic regression analysis, it is likely that all factors influencing selection bias were not accounted for in this analysis. Furthermore, the heterogeneity of the study population may make it difficult to draw broad conclusions on the basis of these data. The current database did not have certain preoperative laboratory values (eg, albumin or prealbumin) that may provide a more definitive objective assessment of malnutrition. Finally, important operative variables were not available, such as echocardiographic parameters, patient prosthesis mismatch, or small prostheses, which have been shown to affect long-term survival in certain subgroups.

\section{CONCLUSIONS}

Patients with low BMI experienced greater in-hospital and long-term mortality when compared with other BMI groups in this single-center study. Outcomes were independent of valve procedure and concurrent CABG. These patients warrant careful risk stratification and may require more intensive preoperative testing. When possible, preoperative conditioning and nutrition enhancement may improve short- and long-term outcomes. Further studies dissecting the causal relationship of low BMI and poor outcomes in patients undergoing cardiac valve surgery are warranted.

The authors from Emory University thank staff members Kim Baio for project oversight, Jean Walker and Susan Joyce for data abstraction, and Deborah Canup for database management.

\section{References}

1. Kumanyika SK, Obarzanek E, Stettler N, Bell R, Field AE, Fortmann SP, et al. Population-based prevention of obesity, the need for comprehensive promotion of healthful eating, physical activity, and energy balance. A scientific statement from American Heart Association Council on Epidemiology and Prevention, Interdisciplinary Committee for Prevention (formerly the Expert Panel on Population and Prevention Science). Circulation. 2008;118:428-64.

2. Flegal KM, Graubard BI, Williamson DF, Gail MH. Excess deaths associated with underweight, overweight, and obesity. JAMA. 2005;293:1861-7.

3. Fonarow GC, Srikanthan P, Costanzo MR, Cintron GB, Lopatin M, ADHERE Scientific Advisory Committee and Investigators. An obesity paradox in acute heart failure: analysis of body mass index and inhospital mortality for 108,927 patients in the Acute Decompensated Heart Failure National Registry. Am Heart J. 2007;153:74-81.

4. Birkmeyer NJ, Charlesworth DC, Hernandez F, Leavitt BJ, Marrin CA, Morton JR, et al., for the Northern New England Cardiovascular Disease Study Group. Obesity and risk of adverse outcomes associated with coronary artery bypass surgery. Circulation. 1998;97:1689-94.

5. Gurm HS, Whitlow PL, Kip KE, for the BARI Investigators. The impact of body mass index on short- and long-term outcomes in patients undergoing coronary revascularization: insights from the Bypass Angioplasty Revascularization Investigation (BARI). J Am Coll Cardiol. 2002;39:834-40.

6. Turer AT, Mahaffey KW, Honeycutt E, Tuttle RH, Shaw LK, Sketch MH Jr, et al. Influence of body mass index on the efficacy of revascularization in patients with coronary artery disease. J Thorac Cardiovasc Surg. 2009;137:1468-74.

7. Jin R, Grunkemeier GL, Furnary AP, Handy JR Jr, for the Providence Health System Cardiovascular Study Group. Is obesity a risk factor for mortality in coronary artery bypass surgery? Circulation. 2005;111:3359-65.

8. Habib RH, Zacharias A, Schwann TA, Riordan CJ, Durham SJ, Shah A. Effects of obesity and small body size on operative and long-term outcomes of coronary artery bypass surgery: a propensity-matched analysis. Ann Thorac Surg. 2005;79: 1976-86.

9. Reeves BC, Ascione R, Chamberlain MH, Angelini GD. Effect of body mass index on early outcomes in patients undergoing coronary artery bypass surgery. J Am Coll Cardiol. 2003;42:668-76.

10. Kuduvalli M, Grayson AD, Oo AY, Fabri BM, Rashid A. Risk of morbidity and in-hospital mortality in obese patients undergoing coronary artery bypass surgery. Eur J Cardiothorac Surg. 2002;22:878-93.

11. Sun X, Hill PC, Bafi AS, Garcia JM, Haile E, Corso PJ, et al. Is cardiac surgery safe in extremely obese patients (body mass index 50 or greater)? Ann Thorac Surg. 2009;87:540-7.

12. Stamou SC, Nussbaum M, Stiegel RM, Reames MK, Skipper ER, Robicsek F, et al. Effect of body mass index on outcomes after cardiac surgery: is there an obesity paradox? Ann Thorac Surg. 2011;91:42-7.

13. Rahmanian PB, Adams DH, Castillo JG, Chikwe J, Bodian CA, Filsoufi F. Impact of body mass index on early outcome and late survival in patients undergoing coronary artery bypass grafting or valve surgery or both. Am J Cardiol. 2007;100: 1702-8. Epub 2007 Oct 24.

14. van Venrooij LMW, de Vos R, Borgmeijer-Hoelen MMMJ, Haaring C, de Mol BAJM. Preoperative unintended weight loss and low body mass index in relation to complications and length of stay after cardiac surgery. Am J Clin Nutr. 2008;87:1656-61.

15. Engelman DT, Adams DH, Byrne JG, Aranki SF, Collins JJ Jr, Couper GS, et al. Impact of body mass index and albumin on morbidity and mortality after cardiac surgery. J Thorac Cardiovasc Surg. 1999;118:866-73.

16. Christakis GT, Weisel RD, Buth KJ, Fremes SE, Rao V, Panagiotopoulos KP, et al. Is body size the cause for poor outcomes of coronary artery bypass operations in women? J Thorac Cardiovasc Surg. 1995;110:1344-58. 
17. Potapov EV, Loebe M, Anker S, Stein J, Bondy S, Nasseri BA, et al. Impact of body mass index on outcome in patients after coronary artery bypass grafting with and without valve surgery. Eur Heart J. 2003;24:1933-41.

18. O'Brien SM, Shahian DM, Filardo G, Ferraris VA, Haan CK, Rich JB, et al. The Society of Thoracic Surgeons 2008 cardiac surgery risk models: part 2 - isolated valve surgery. Ann Thorac Surg. 2009;88:S23-42.

19. Tyson GH 3rd, Rodriguez E, Elci OC, Koutlas TC, Chitwood WR Jr, Ferguson TB, et al. Cardiac procedures in patients with a body mass index exceeding 45: outcomes and long-term results. Ann Thorac Surg. 2007;84:3-9.

20. Wigfield CH, Lindsey JD, Muñoz A, Chopra PS, Edwards NM, Love RB. Is extreme obesity a risk factor for cardiac surgery? An analysis of patients with a BMI $>$ or $=40$. Eur J Cardiothorac Surg. 2006;29:434-40.

21. Romero-Corral A, Montori VM, Somers VK, Korinek J, Thomas RJ, Allison TG, et al. Association of bodyweight with total mortality and with cardiovascular events in coronary artery disease: a systematic review of cohort studies. Lancet. 2006;368:666-78
22. Allison DB, Faith MS, Heo M, Kotler DP. Hypothesis concerning the U-shaped relation between body mass index and mortality. Am J Epidemiol. 1997;146: 339-49.

23. Ranucci M, Pazzaglia A, Bianchini C, Bozzetti G, Isgrò G. Body size, gender, and transfusions as determinants of outcome after coronary operations. Ann Thorac Surg. 2008;85:481-6.

24. Rich MW, Keller AJ, Schechtman KB, Marshall WG, Kouchoukos NT. Increased complications and prolonged hospital stay in elderly cardiac surgical patients with low serum albumin. Am J Cardiol. 1989;63:714-8.

25. Abel RM, Fisch D, Horowitz J, van Gelder HM, Grossman ML. Should nutritional status be assessed routinely prior to cardiac operation? J Thorac Cardiovasc Surg. 1983;85:752-7.

26. Fried LP, Tangen CM, Walston J, Newman AB, Hirsch C, Gottdiener J, et al., for the Cardiovascular Health Study Collaborative Research Group. Frailty in older adults: evidence for a phenotype. J Gerontol A Biol Sci Med Sci. 2001;56: M146-56 